\title{
Language Competence in a Puzzle of Modern Russian Vocational Education
}

\author{
Vladislav Vladislavovich Serikov ${ }^{1}$, Elena Alexandrovna Loktyushina ${ }^{1}$ \& Viktoria Konstantinovna Pichugina ${ }^{1}$ \\ ${ }^{1}$ Teacher Training Department, Volgograd State Socio-Pedagogical University, Volgograd, Russia \\ Correspondence: Vladislav Vladislavovich Serikov, Teacher Training Department, Volgograd State \\ Socio-Pedagogical University, 27 Lenin Avenue, 400066 Volgograd, Russia. E-mail: pichugina-v@list.ru
}

Received: September 12, 2014 Accepted: October 17, 2014 Online Published: November 26, 2014

doi:10.5539/ies.v7n12p37 URL: http://dx.doi.org/10.5539/ies.v7n12p37

\begin{abstract}
The article shows that foreign language skills influence the professional success in a globalized economy. Training experts who are able to use foreign languages at the level required for professional communications is highly urgent for today's Russia, however there is hardly any experience of training such experts in accordance with international standards in most Russian universities. In this regard the authors propose to change the structure of professional education and criteria of assessing the professional competence of an expert. A competence in using a foreign language as a tool for interaction with partners and solving professional problems should become an integral part of the content of vocational education. A foreign language should be mastered as a tool of solving professional tasks, while language training should be organized on the basis of modeling key professional communicative situations. Besides, unwillingness to communicate professionally with foreign partners must be considered as manifestation of professional incompetence of a specialist. The authors point out that such model of professional training with a foreign language included in its structure is the most important for countries seeking integration into the world economy.
\end{abstract}

Keywords: vocational education, foreign language competence, professional and foreign language experience, professional communicative tasks-situations

\section{Introduction-The Problems of Professional and Foreign Language Training: Background}

Strengthening integration trends in modern civilization, the dynamics of social life and the associated new objectives, scope and direction of the reforms require the training of specialists, who practically speak one or more foreign languages.

Participation in international economic and social structures implies effective using of a foreign language for solving professional communicative tasks. In this case foreign language competence should become an essential component of professional training content. Implementation of benchmarking principles, orientation to the highest world achievements, contractual relations and international projects have already become a standard for advanced manufacturing enterprises. These trends have led to reviewing the content and technology of modern vocational education in Russia. Specialist who is not prepared to work in today's global economic and technological environment using a foreign language is considered incompetent. It is impossible to respond quickly to market situations, cooperate and negotiate with partners without foreign language strategies. Language competence is recognized today as the most significant competence of a specialist.

Integration of developing economies into the world economic environment requires a real and virtual collaboration with foreign partners, participation in international exhibitions, presentations, and conferences. It has become a daily reality in the lives of modern specialists. According to estimation of reputable managers of transnational corporations, the ability to communicate, to establish favorable relations very often proves to be not less important precondition of personal and professional success than technical competence.

The new economy requires teamwork and the abilities to cooperate in unclear environments, to solve problems, to deal with non-routine process, to communicate effectively, and to see the workplace environment in a broader context. Workers must function beyond what is expected of them, and must possess those skills that they need to survive in the changing economy (Bakar, Shamsiah, \& Hamzah, 2013).

Thus, the processes of globalization have led to creation of a multinational model of the economy where 
industrial and market success depends on the ability of professionals to function effectively in a multilingual environment. An important feature of modern business today is that most of professional solutions require a humanitarian, cultural and language competences of modern specialists.

Professional foreign language competence of a specialist is becoming a factor of his status growth, and language policy provided by the company is considered now to be an important factor of its market position.

\section{Literature Review}

The purpose of vocational education today is to prepare a specialist for whom a foreign language is one of the basic tools of professional activity and a means of personal development. Researchers in the field of vocational education point out that the main purpose of vocational education is not only in acquisition skills and knowledge but in finding the answer to the question how these skills and knowledge are combined with personal qualities when it comes to choosing a particular job. A sense of 'suitability' for a certain type of work is constructed socially and culturally, and in this case vocational education-from recruitment through to qualification and labour market entry-plays a powerful role in that process, mediating between classed-gendered backgrounds and the demands of the Workplace (Colley, James, Diment, \& Tedder, 2003).

However, if the authors agree on the role of vocational education, they have different opinions about its place in the system of specialist training. According to some authors, one may consider vocational education and training to be the development and application of knowledge and skills for middle level occupations needed by society from time to time. This definition relies on the concept of applied knowledge as if Aristotle's notion of art or applied science (techne) is adequate, which it clearly isn't without elaboration. It also locates vocational education and training by occupational level thus making it subject to shifts in occupational hierarchy and economic structure. While it would be more satisfying to locate vocational education and training by educational level, this is probably the preference of an educationalist not shared by employers, workers and government (Moodie, 2002).

Besides, policies need to also be concerned with perceptions of VET, young people's needs and successful outcomes, and not only focused on responding to current and future labour market needs. To this end however, more research is needed on the trajectories of young people who are in VET programs and who have graduated from them (Molgat, Deschenaux, \& LeBlanc, 2011).

There are also some negative trends that accompany vocational education in our time. Researchers are worried about "marginalization" of vocational education in some schools. The data presented in their study suggest that the immediate concern in the context of VET delivery in this school is not so much its socially selective characteristics, but its poor quality. There is no suggestion in the views of students or teachers that VET is not required or that it should be abandoned, but rather that its status should be raised, its quality improved and its role in creating pathways more carefully considered (Polesel \& Clarke, 2011).

Ways to improve the status of vocational education are being looked everywhere. According to experts from Saudi Arabia it is arguable whether successful review of the vocational education system can be realised, or the skills gap reduced, without concurrent shifts in wider social and cultural attitudes towards employment and training (Baqadir, Patrick, \& Burns, 2011).

Differences also arise in the clash of interests of professional and educational bodies in the organization of the internship. In general, the idea of the representatives of the labor market according to the forms of cooperation, venue, duration, and the criteria for assessing the effectiveness of internship remain unchanged (Akomaning, Voogt, \& Pieters, 2011).

Nevertheless, all the authors agree on the need to coordinate efforts to develop common approaches and requirements to vocational training. As it is pointed out, Universities, governmental organizations and employers' associations need to get together to create a uniform set of short, straightforward and easily memorable definitions of key skills in order to facilitate shared understanding. Consensus in this regard on the parts of universities, government organizations and employers can only be to the benefit of future graduates (Bennett, 2002).

Only joint efforts of governments and educational bodies can guarantee the graduates good career prospects. They should be equipped with skills that will let them make a successful career in life. The students should plan their career properly, and design their educational trajectory in such a way that, by the time they complete their graduation, they become qualified to avail of all the opportunities required for making successful career (Miroshnichenko \& Gaivoronskaya, 2014). 


\section{Materials and Methods}

Training of specialists for whom a foreign language is an essential tool of professional activity and evidence of their cultural position is a new type of vocational education in Russia. Its implementation in practice meets many difficulties. The reason of it is that neither nature nor the psychological mechanisms of developing this competence are still not sufficiently known to science.

And it's not because Russian vocational education does not have effective methods of teaching foreign languages but because this experience is not included in the scope of professional activities, in the system of tasks and competences of a future specialists! Such approach demands not only reconstruction of language training, but reconstruction of general vocational education. Inclusion in its structure specific types of experience (tasks, activities, etc.) still presents a problem for pedagogical theory and practice in Russia.

Mastering this competence cannot be achieved within the traditional discipline "Foreign Language". It requires new practical training modules that form professional experience in solving communication problems on the basis of orientation in professional and language situations. Inclusion of such competence in vocational education structure in this situation can be considered as important resource of social and economic development of the country, factor of cultural and intellectual development of the individual. There is an urgent need to bring the language policy to the new realities of society, to work out a new content and technology of vocational education.

In Russian higher school the traditional model of "professional orientation" of language education still means the study of specialized vocabulary and using texts with a professional content. It has nothing to do with using a foreign language as a tool for solving professional problems while doing projects, working with international databases and contacting with foreign partners. In this regard, the level of professional foreign language competence of graduates of Russian universities in comparison with the level of European specialists (estimated by competent experts) continues to be very low.

The main reason of apparent difficulties in effective foreign language communication in a professional environment is seen in the lack of unity in mastering linguistic and professional experience in the process of professional socialization of a specialist. As surveys show many Russian students do not see the prospects of using a foreign language in their professional activities because they are offered the outdated model of this activity where its instrumental role is not presented. A training process doesn't correlate with the reality in which future professionals will realize their potential.

Until we realize that without knowledge a foreign language we can't imagine neither education nor the professionalism, as it was in educational traditions of the 19th century, our vocational education won't correspond to the world standards of production. Considering a foreign language as one of the factors of professional activity (in its modern sense), it is necessary to investigate the specificity of professional discourse, corresponding forms of business cooperation, and those kinds of experiences-the actual language and operational, that should be assimilated in the process of language training.

It should be noted that the overwhelming majority of university teachers in Russia nowadays are not ready to create linguistic and professional environment. Sometimes they are not able to make informed decisions about language and language training. They are lack of credibility, professionalism, and an awareness of the business world. Above all, they have difficulties in adapting to a particular teaching context and do not will to learn.

According to surveys the profession of a teacher and its social status carries little or no respect in society. Moreover, there is an opinion that those people tend to become teachers who "did not find their place" in commercial companies or in the sphere of public administration (Fursova \& Simons, 2014).

Thus, the objective of our study was to develop models and techniques of vocational education, in which the use of language is becoming one of the leading professional competences.

The following research methods were used: standardized tests of language proficiency, modeling speech situations on the basis of discourse analysis of professional work, study and conceptualization of practical experience, the design and testing of educational technologies, pilot experiment, developing experiment.

In addition to CEFR tests (Table 2) used to identify the input level of linguistic competence, we diagnosed motivation of choosing a particular occupation. We considered it important as such kind of motivation determines a certain level of personal claims based on assessment of abilities. Besides it demands the ability to evaluate personal qualities as factors of occupational choice and form a hierarchy of individual factors. The concept of motivation is observable thorough peoples' behaviour in everyday life and psychologists have developed various procedures for assessing it (Keaney \& Mundia, 2014). For this purpose we used interviewing 
as it allowed identifying the leading motive for choosing a profession based on an assessment done by students according to their own personal qualities.

The reasons of learning General English and English for Specific Purposes were also revealed. It was done with the help of set of diagnostic methods which helped to understand if learners see a sense of language training and how and where they intend to use linguistic knowledge and skills in their career.

To predict training outcomes and get a clear picture of the inclusion of specific types of intelligence each individual possesses, we found it necessary to determine leading types of intelligence based on Gardner methods (the results of this research are represented in Table 3). Very often the success of learning depends on how students see their role in a learning process, how they build interpersonal relations and if they are confident in positive results. The world of personal relation determines the degree of our feelings towards and our satisfaction with our success. In this case, the success means that one may express his/her feelings well, may live and work independently, may be rigid and may have self-confidence in expressing his/her feelings and belief (Supardi, 2014).

Apart from this, external factors and internal conditions of developing integrated professional and foreign language competence were studied. They are: content of state educational standards, the amount and distribution of teaching hours in the subjects of social and humanitarian cycles, the impact of the educational environment of high school on the motivational sphere of students.

\section{The Reasons of Failure in Language Training of Modern Russian Specialists}

Summarizing the stated above, and basing on the results of our own research conducted in Volgograd State Social Pedagogical University, we can conclude that the reasons for the low level of language skills of modern Russian specialists are the following: 1) lack of holistic view on the system of linguistic development of a specialist - historical, cultural, mental, environmental, didactic; 2) existing educational mentality with the possibility of vocational education without foreign language training; 3) inefficiency of simulation of professional language in the educational environment, where students are not involved in professional discourse; 4) traditional comprehension of the role and place of the subject "Foreign Language" in the system of vocational training as the Humanities, designed to expand the overall outlook of students; 5) absence of clear statement of training objectives based on the type of professional activities that require the use of language; 6) lack of the components in the content of language training (problems, reproductive and creative types of experience) involving actual experience of professional communication; 7) insufficient amount of time given to the study a foreign language in the structure of educational programs; 8) lack of special training of foreign language teachers for non-linguistic faculties of universities who are not ready to model appropriate professional situations, and a virtual absence in the Russian higher school teachers who are ready to conduct teaching vocational disciplines in a foreign language; 9) low level of language education in Russian secondary school, which doesn't allow developing language for professional purposes; 10) insufficient development of methods of teaching a foreign language in integrative connection with vocational training.

\section{Integration of Linguistic Competence in the Content of Vocational Education}

It is possible to overcome this negative situation if to change goals and content of vocational education with a focus on the construction a multidimensional model of professional activity with the language component included. This model of professional activity reflects its nature. The function of foreign language communication is in identifying the internationally recognized samples of solving professional tasks, searching new ideas and technologies. At the same time the most important goal of training is not only to develop experience in language situations but also to create a belief that it is impossible to be professionally efficient in the modern world without a foreign language!

Thus, the goal of foreign language education in higher school is developing foreign language competence integrated into the structure of professional activity. A sample program of the subject "Foreign Language" for Bachelor Degree considers formation of professionally oriented intercultural communicative competence as an ultimate goal of mastering a foreign language. Professional experience including a subsystem of linguistic behavior in a professional environment is acquired by solving a set of vocational and communicative tasks in professionally oriented situations. This situation is 1) a set of objective factors encouraging and mediating the activity of a person or a group; 2) description of a specific situation offered to learners to acquire experience of decision-making in such circumstances; 3 ) an experience of interaction with non-native partners in the context of solving professional problems.

The following tasks are involved in such kinds of situations: 1) establishing a contact with the partners in terms 
of interpretation professional problems ("task for comprehension"); 2) developing a project that requires coordination of economic interests and technological capabilities of the partners ("task for designing"); 3) developing new technologies and principles of production in the form of training support from one of the partners ("task for perception and transfer of expertise"); 4) harmonization of criteria and procedures for evaluating the efficiency of production and quality of the product, its marketing parameters ("task for identifying characteristics of a product"); 5) identifying and assessing the cultural peculiarities of business partners for developing mutually acceptable standards of cooperation ("task for the dialogue of cultures").

Integration of foreign language experience in the structure of professional activity is achieved by mastering professional and personal sense of communicative experience, indicative basis for implementing various kinds of professional communicative activities. The process of solving a sequence of increasingly complex professional and communicative tasks requires specific abilities from a learner.

The first ability required in order to successfully communicate in an occupational setting is the ability to use the particular jargon characteristic of that specific occupational context. The second is the ability to use a more generalized set of academic skills, such as conducting research and responding to memoranda. This is largely related to understanding a new culture. The third is the ability to use the language of everyday informal talk to communicate effectively, regardless of occupational context.

The first task as "task for comprehension" is related to the establishment of information and psychological understanding between partners in terms of interpretation of professional problems. This situation requires from a specialist not only translating competence, but also a proper professional competence, that is the ability to express the essence, scope, and class of problem, to find its analogues in technical devices or organizational structures of the company. Besides, an adequate speech form must be given to these utterances in accordance with professional terminology.

The second task marked as "task for designing" is related to the implementation of design, planning procedures, harmonization of regulatory work and resources, economic interests and technological capabilities of partners. Here a specialist must also use professional speech constructions and definitions, reflect and formulate technical ideas that is impossible without knowledge of professional language.

The third task is the perception of a problem and transferring experience in the form of new technologies and principles of production. Large modern corporations see their vital organizational management function in training their employees to obtain the best world experience. It is impossible to implement this task without foreign language skills.

The fourth task, according to our model, is related to the harmonization of criteria and procedures for evaluating production efficiency and product quality, its marketing parameters ("task for identifying characteristics of a product"). Here partners agree on the best conditions of product support. Only a specialist can be a true expert and define the quality of a product by finding the most compelling and effective ways of verbal presentation of marketing characteristics of a product. It should be done not only for the sale, but also for attracting investment into its production.

And finally, the fifth task included in the basic communicative situation is the task of identifying and assessing cultural features of business partners, developing mutually acceptable standards of cooperation ("task for the dialogue of cultures"). Practice of cooperation shows the importance of mutual adaptation of specialists. Meeting this challenge requires the highest level of proficiency.

If to interpret the content of vocational education as a set of types of experiences that learners must master, then, professional activity should become a source of this content. It is based not only on technological progress, but also is influenced by all spheres of public culture, including the impact of national traditions, mentality.

With this view, the content of vocational education should combine the following types of experience: 1) experience of behavior in situations where the outcome depends on effective interaction with foreign partners; 2) experience of interaction with foreign partners in creating and implementing a project; 3) experience in developing and implementing quality products; 4) experience in assessing the quality of the product, its marketing characteristics and conditions of sale (liquidity); 5) experience in adapting to the ethno-cultural characteristics of partners.

Thus, the purpose of organically bound vocational and language education is the developing professional competence by integrating linguistic experience in the structure of professional activity.

Integrated professional and foreign language competence as a goal of vocational education includes integrated professional and linguistic experience, which is a system of subject knowledge, awareness of ways of 
functioning in a professional environment on the basis of mastering a foreign language as an integral part of culture and professional tool.

The content of vocational education is originally designed as an integrated framework where linguistic competence plays the same role in solving professional problems like any other component of professional training. And the absence of this component has the same negative consequences for professional growth as non-possession of professional competence. Content of vocational education in accordance with this model includes an integrated construct of professional and foreign language competence and is composed of professional experience, which appears as meta subject experience containing both operational and linguistic substructures. For example, for management students the basic vocational and language problems are implemented in the situations simulating the development of corporate and competitive strategy of the organization. They also concern the complex of operational activities in accordance with the company's strategy, team building for specific projects, motivating staff and encouraging people to achieve strategic and operational objectives. Besides, these problems cover developing business plans of international economic activity and establishing joint entrepreneurship programs.

To develop criteria of such integrated professional and foreign language competency we used the description of professional competences from Russian Standards of Higher Vocational Education and the description of language competences from CEFR. As a basis for determining the degree of development of integrated professional and foreign language competency we used the principle "I can" applied for description of levels of language possession in CEFR.

The development of a diagnostic English speaking test with high reliability and validity will enable teachers to diagnose the strengths and weaknesses of students' English speaking ability, which can help them to determine appropriate types and levels of teaching and learning activities and improve teaching efficiency (Zhao, 2014).

From the standards of Management, Human Resources Management, Economy specialties we have identified the main professional competences, in developing of which the discipline Foreign Language is involved. This table presents the skills and knowledge that form the structure of professional competence of future human resources managers.

Table 1. The structure of professional competence

\begin{tabular}{|c|c|c|c|}
\hline $\begin{array}{l}\mathrm{C} \\
\mathrm{O} \\
\mathrm{M} \\
\mathrm{P} \\
\mathrm{T} \\
\mathrm{E}\end{array}$ & $\begin{array}{l}\text { Student knows: } \\
\text { - main types of } \\
\text { companies, } \\
\text { structure, } \\
\text { positions; } \\
\text { - basic } \\
\text { of free enterprise } \\
\text { system; } \\
\text { - basic types of } \\
\text { property; } \\
\text { - principles } \\
\text { entrepreneurship; } \\
\text { - names of main } \\
\text { currencies, Commodity } \\
\text { Exchanges } \\
\text { financial institutions; } \\
\text { - marketing complex } \\
\text { and } \quad \text { marketing } \\
\text { operations; } \\
\text { - main concepts and } \\
\text { functions } \\
\text { management; } \\
\text { - main concepts and }\end{array}$ & $\begin{array}{l}\text { Student can: use the acquired knowledge for imitating } \\
\text { basic kinds of professional activity: (self-presentation } \\
\text { and presentation of business, telephone talks, "small } \\
\text { talk", arranging time and place of meeting, making } \\
\text { business proposal, accepting and refusing proposal, } \\
\text { bargaining, making advertisement, making job advert, } \\
\text { composing resume and memorandum). }\end{array}$ & $\begin{array}{l}\text { Student possesses the } \\
\text { following strategies on } \\
\text { the basis of acquired } \\
\text { knowledge and skills: } \\
\text { - holding formal and } \\
\text { informal talks; } \\
\text { - professional } \\
\text { self-presentation and } \\
\text { presentation } \\
\text { business; } \\
\text { - assessing the } \\
\text { importance of each } \\
\text { position in the } \\
\text { organization; } \\
\text { - singling out general } \\
\text { and specific } \\
\text { characteristics; } \\
\text { - comparing on the } \\
\text { basis of analysis of the } \\
\text { main forms } \\
\text { organizational of } \\
\text { activities; } \\
\text { - determining the most } \\
\text { rational approach to the }\end{array}$ \\
\hline
\end{tabular}




\begin{tabular}{|c|c|c|}
\hline $\begin{array}{l}\mathrm{N} \\
\mathrm{C} \\
\mathrm{E}\end{array}$ & $\begin{array}{l}\text { laws of macro and } \\
\text { microeconomics. }\end{array}$ & $\begin{array}{l}\text { business organization; } \\
\text { - forecasting the } \\
\text { development of the } \\
\text { situation and their own } \\
\text { actions; } \\
\text { - ability to make } \\
\text { situation analysis and } \\
\text { analysis of events and } \\
\text { details, } \\
\text { - ability to publicly } \\
\text { speaking with the } \\
\text { presentation of the } \\
\text { product advertised; } \\
\text { - ability to solve } \\
\text { managerial tasks on the } \\
\text { basis of analysis of } \\
\text { marketing operations; } \\
\text { - management team } \\
\text { building; } \\
\text { - ability to make } \\
\text { comparative analysis of } \\
\text { different types of } \\
\text { production; } \\
\text { - ability to identify } \\
\text { cause-and-effect } \\
\text { relationships; } \\
\text { - ability to serve } \\
\text { searching for } \\
\text { information in foreign } \\
\text { sources. }\end{array}$ \\
\hline
\end{tabular}

The content of education reflects the unity and integrity of linguistic and professional experience and is implemented at three levels: meta subject, subject and task-situational.

Meta subject level of education is represented by interdisciplinary modules and has the form of solving problems based on professional and linguistic experience. These modules are necessary to guide the students into their future profession. They are integrated into the context of international projects and aimed at further development of the individual speech behavior universal strategies for functioning in a global manufacturing environment.

Subject level of education is implemented by academic disciplines (taught in a foreign language), and by "Foreign Language" discipline. At this level a future specialist masters a set of competencies combining subject knowledge and methods of its application for professional use. The effectiveness of solution depends on the ability to present the scope of professional interests in a foreign language that provides new opportunities for achieving goals.

Task-situational level is implemented by problems and situations and involves the development of techniques and tools for solving specific professional tasks. It also requires skills in vocational and language environment by modeling and varying verbal behavior.

Thus, linguistic competence with substantial grounds can be identified as integral professional competence.

\section{The Progress and Outcomes of the Experiment}

Before the beginning of the experiment we determined criteria of professional and linguistic competence. They are: 1) awareness of the importance of interaction with partners; 2) ability to present professional information and transmit it to consumers; 3) considering national traditions of foreign partners; 4) possession of orienting basis and verbalization skills of professional experience; 5) system knowledge of professional language 
(ownership of bilingual professional discourse).

To determine the input level of professional and linguistic competence the above criteria were used. We also used the test which allowed distributing students in accordance with the levels of language proficiency developed by the Council of Europe. Testing showed that language level of freshmen of the Faculty of Economics and Management of Volgograd State Social Pedagogical University (191 students) corresponds to two levels of English proficiency: elementary and advanced (A and B). Analysis of test results revealed the distribution of students within each of these levels: the level of survival A1 (77 students-40\%), pre-threshold level A2 (77 students-40\%), the threshold level B1 (36 students-18.8\%) and advanced level B2 (1 student-1.2\%). We also diagnosed other parameters as: initial motivation of choosing profession, reason for foreign language study, leading type of intelligence.

Table 2. The results of diagnostic parameters of the initial state of foreign language competence of students

\begin{tabular}{llll}
\hline Characteristics/factor & Methods & Indicators & Results \\
\hline & & B2 & $1,2 \%$ \\
Input Level of Language Competence & CEFR testing & B1 & $18,8 \%$ \\
& & A2 & $40 \%$ \\
& & A1 & $40 \%$ \\
\hline
\end{tabular}

Table 3. The results of diagnosing factors influencing on developing professional and foreign language competence

\begin{tabular}{cccc}
\hline Characteristics/factor & Methods & Indicators & Results \\
\hline \multirow{2}{*}{$\begin{array}{c}\text { Initial Motivation of Choosing } \\
\text { Profession }\end{array}$} & Method of S. & Prestige & $11 \%$ \\
& Grinshpun & Well-being & $56 \%$ \\
Reasons of Foreign Language Study & Method of A. Rean & Creative Self-realizing & $33 \%$ \\
& & Chtention of Self-development & $50 \%$ \\
& & Cuccess of professional & activity \\
Leading Type of Intelligence & Method of G. & Mixed intelligence & More than \\
& Gardner & Logical mathematical & $40 \%$ \\
& & intelligence & About 30\% \\
& & Musical intelligence & About 30\% \\
\hline
\end{tabular}

Three stages of formation of professional competence with linguistic component included have been allocated: 1) mastery of the conceptual apparatus of the profession; 2) mastery of professional functions at the level of solving the basic professional communicative tasks using a foreign language; 3) priority of the functional aspect of foreign language communication as a means of professional self-realization.

The first stage was connected with forming primary experience of mutual understanding with partners; the second one was dealt with acquiring experience in solving major professional communicative tasks using a foreign language; the third developed the ability to use a foreign language as a means to achieve goals and provide professional growth. For each stage assignments, exercises, methods of simulation the situations of professional communication in a foreign language appropriate to the aims were developed.

Final tests and a series of credit assignments at every stage showed that in the experimental group $32 \%$ of those participated in the experiment showed pre-threshold level of formation of professional foreign language 
competence, $42 \%$-the threshold, and 26\%-advanced. In the control group, $53 \%$ stayed at pre-threshold level.

\section{Results}

In conclusion we present the main results of research.

1) A new model of educational content (for example, management experts) representing the unity of language and professional experience was developed. This model provides an effective solution of the following tasks: understanding a partner; developing a project that requires coordination of economic interests and technological capabilities of the partners; perception and transmission of ideas and experience; harmonization of criteria and procedures for evaluating production efficiency and product quality; development of mutually acceptable rules of cooperation. Possession of specified competencies in the unity with professional English-speaking discourse provides willingness to participate in today's globalized knowledge-based production.

2) Technology of forming professional linguistic competence to solve professional communicative tasks was worked out. It provides a motivation in learning a foreign language not only as a promising career, but also for the daily operation in the industrial sector with corresponding interethnic contacts, and experience of making decision in different kinds of situations.

3) Methods of overcoming the existing contradiction between expanding interethnic communication in real and virtual production environment and the available linguistic experience which needs continuous improvement were develped. The lack of such experience creates difficulties and tension for a future specialist in situations of negotiation, decision-making, contracting, when the success is determined by his ability to participate in foreign language professional communication.

4) While providing research, self-study programs and programs of self-development were created for the students and teachers. They are realized through the establishment of the university international project environment - areas of professional foreign language communication and design.

5) Samples of educational programs and modules constructed in accordance with the idea of the integration of language and vocational competencies of future specialists were created and tested. With a view of implementing such programs in traditional and distance training, consulting the teachers preparing to teach their courses in a foreign language is being provided.

In fact, professional activity of a special form has become a priority component of interaction with partners and the various sources of professionally relevant information. Without possessing tools of communication, the most important of which is a foreign language, occupational functioning and development in such environment proves ineffective and inadequate. The proposed variant of the construction of vocational education is based on notions of professional activity in the context of globalization of production and consumption, and revives the classical idea of education. This modern model differs from the traditional one where language proficiency is becoming a sign not only of cultural, but also professional efficiency of a specialist.

\section{Conclusion}

Besides the development of models and techniques of foreign language training (on the example of training specialists in the field of management), the research identified a number of issues specific to the Russian educational situation. They are: 1) the need to move to teaching vocational subjects or their sections in a foreign language, to which the majority of teachers of Russian universities are not ready; 2) development of new standards of vocational education integrating language competence in the structure of professional activity; 3 ) development of technologies of mastering profession in the integrity with acquisition language and professional experience in occupational communication.

\section{Acknowledgements}

This work was supported by Rector of Volgograd State Social Pedagogical University, Corresponding Member of the Russian Education Academy, Ph.D in Teacher training, N. Sergeev, Director of Foreign Languages Institute, Ph.D in Teacher training, L. Milovanova, Director of International Institute of Educational Innovations at Russian State Pedagogical University, Ph.D in Teacher training, N. Grokhovatskaya. The research was conducted with support of The Ministry of Education and Science of the Russian Federation in the context of basic section of the state command №2014/411 (project number: 919).

\section{References}

Akomaning, E., Voogt, J. M., \& Pieters, J. M. (2011). Internship in vocational education and training: Stakeholders' perceptions of its organization. Journal of Vocational Education \& Training, 63(4), 575-592. http://dx.doi.org/10.1080/13636820.2011.590222 
Bakar, A. R., Shamsiah, M., \& Hamzah, R. (2013). An Assessment of Workplace Skills Acquired by Students of Vocational and Technical Education Institutions. International Education Studies, 6(11), 15-20. http://dx.doi.org/10.5539/ies.v6n11p15

Baqadir, A., Patrick, F., \& Burns, G. (2011). Addressing the skills gap in Saudi Arabia: Does vocational education address the needs of private sector employers? Journal of Vocational Education \& Training, 63(4), 551-561. http://dx.doi.org/10.1080/13636820.2011.589533

Bennett, R. (2002). Employers' Demands for Personal Transferable Skills in Graduates: A content analysis of 1000 job advertisements and an associated empirical study. Journal of Vocational Education \& Training, 54(4), 457-476. http://dx.doi.org/10.1080/13636820200200209

Colley H., James, D., Diment, K., \& Tedder, M. (2003). Learning as becoming in vocational education and training: Class, gender and the role of vocational habitus. Journal of Vocational Education \& Training, 55(4), 471-498. http://dx.doi.org/10.1080/13636820300200240

Fursova, V., \& Simons, G. (2014). Social Problems of Modern Russian Higher Education: The Example of Corruption. International Education Studies, 7(10), 25-31. http://dx.doi.org/10.5539/ies.v7n10p25

Keaney, M., \& Mundia, L. (2014). Foreign Language Learners' Motivation and Its Effects on Their Achievement: Implications for Effective Teaching of Students Studying Japanese at Universiti. International Education Studies, 7(9), 122-135. http://dx.doi.org/10.5539/ies.v7n9p122

Miroshnichenko, O. I., \& Gaivoronskaya, Y. V. (2014). Creating Professional Skills through Modern Higher Education. International Education Studies, 7(9), 50-55. http://dx.doi.org/10.5539/ies.v7n9p50

Molgat, M., Deschenaux, F., \& LeBlanc, P. (2011). Vocational education in Canada: Do policy directions and youth trajectories always meet? Journal of Vocational Education \& Training, 63(4), 505-524. http://dx.doi.org/10.1080/13636820.2011.580361

Moodie, G. (2002). Identifying vocational education and training. Journal of Vocational Education \& Training, 54(2), 249-266. http://dx.doi.org/10.1080/13636820200200197

Polesel, J., \& Clarke, K. (2011). The marginalisation of VET in an Australian secondary school. Journal of Vocational Education \& Training, 63(4), 525-538. http://dx.doi.org/10.1080/13636820.2011.580362

Supardi, S. (2014). Teacher Emotional Intelligences: A Demographic Perspective of a Comparational Study of the Teachers at Public Senior High Schools at Tangerang. International Education Studies, 7(10), 112-121. http://dx.doi.org/10.5539/ies.v7n10p112

Zhao, Z. (2014). A Needs-Based Approach to the Development of a Diagnostic College English Speaking Test. International Education Studies, 7(6), 145-153. http://dx.doi.org/10.5539/ies.v7n6p145

\section{Copyrights}

Copyright for this article is retained by the author(s), with first publication rights granted to the journal.

This is an open-access article distributed under the terms and conditions of the Creative Commons Attribution license (http://creativecommons.org/licenses/by/3.0/). 